\title{
DISSIPATION OF FLUROXYPYR IN A MALAYSIAN AGRICULTURAL SOIL WITH SIMULATION USING THE PERSIST AND VARLEACH MODEL
}

\author{
HALIMAH, $\mathbf{M}^{*}$; SULAIMAN, $\mathbf{N}^{*}$; ISMAIL, B $\mathbf{S}^{* *}$ and TAYEB, M $A^{* *}$
}

\begin{abstract}
The study was carried out to compare the dissipation of fluroxypyr in a Malaysian agricultural soil based on field experimentation and simulation using the PERSIST and VARLEACH model. A plot situated in an oil palm plantation near Sepang, Selangor, Malaysia was selected for the field experiment. The plot was treated with fluroxypyr at the recommended dosage $\left(72.5 \mathrm{~g} \mathrm{ha}^{-1}\right)$. The soil samples from the field trial were collected and analyses conducted in the laboratory according to the sampling schedule. Simulation of fluroxypyr persistence and leaching was also conducted using computer-run software, PERSIST and VARLEACH. The predicted data obtained using PERSIST for fluroxypyr was found to be higher than the observed data from field measurements. However, the predicted data for fluroxypyr using VARLEACH matched well with the observed data from the field trial.
\end{abstract}

Keywords: fluroxypyr, soil, dissipation, PERSIST model, VARLEACH model.

Date received: 9 April 2015; Sent for revision: 2 June 2015; Received in final form: 2 November 2015; Accepted: 18 January 2016.

\section{INTRODUCTION}

Pesticide is an essential part of commercial agriculture and side by side it is a big environmental threat. Mathematical models are needed to use for making prediction about pesticide use and gauging environmental risk assessment (Ngim et al., 2000; Cheah et al., 2001). Several models have been developed to simulate the movement and persistence of pesticide residues in soil. These include the pesticide root zone model (PRZM) developed by the United States Environmental Protection Agency and its modified version, PELMO

\footnotetext{
Malaysian Palm Oil Board, 6 Persiaran Institusi,

Bandar Baru Bangi, 43000 Kajang, Selangor, Malaysia.

** School of Environmental and Natural Resource Sciences, Faculty of Science and Technology,

Universiti Kebangsaan Malaysia,

43600 Bangi, Selangor, Malaysia

E-mail: ismail@ukm.edu.my
}

(Ainie et al., 2007), LEACHP, developed at the Cornell University (Farahani et al., 2008; Fuad and Maher, 2010) the more recent version of the CALF model (Buszewski, 2006), then known as VARLEACH (Giacomazzi and Cochet, 2004; Cabrera et al., 2007) and PESTLA, developed in the Netherlands (Boeston, 2000). PERSIST and VARLEACH are specific computer software, which have been used to predict the persistence and leaching of pesticides in soil (Gooddy et al., 2002; Ismail et al., 2004). Given a valid model, expected behaviour under average and extreme conditions could be predicted with a limited amount of experimental data. Persistence of a compound when applied at different times of the year, for different years or at different geographical areas can be assessed using the PERSIST and VARLEACH models.

The ability of a model to predict the behaviour of a pesticide in soil is potentially of great value both to optimise the performance of soil applied 
compounds as well as to anticipate and minimise the risk of adverse environmental effects. Modeling with regard to field behaviour began around 1970 when available tools and techniques enabled dynamic simulation of pesticide behaviour in the soil / plant system (Chefetz et al., 2004). Considerable progress has been made in the development of simulation models for estimating the movement and degradation of agricultural chemicals (Boeston, 2000; Guardia-rubio et al., 2006.). The role of environmental fate modeling of pesticides has increased steadily, and it now plays a major role in the assessment of the environmental aspects of pesticide behaviour for the process of pesticide registration (Mou et al., 2008; Ismail et al., 2015). Meanwhile, a study comparing the dissipation of chlorpyrifos, chlorothalonil and profenofos was conducted in Cameron Highlands, Pahang, Malaysia to assess the difference between field data and predicted data by simulation using the PERSIST model (Liyange et al., 2006).

A mathematical model described by Ying and Kookana (2001) has been shown to be capable of predicting the persistence of a number of herbicides in soil collected from the field, once the rates of degradation have been established for the same soil in the laboratory. The basis of the model developed by Ismail et al. (2004) hinged on the use of data such as temperature and moisture content of the surface soil in the field from weather records, and combining these with laboratory measurements of herbicide degradation rates, for running the program. The original program was written in the simulation language CSMP, 6 for which the daily weather records of soil temperatures at $10 \mathrm{~cm}$ depth, the rate of evaporation from an open water surface (Eo, mm per day) and the rainfall ( $\mathrm{mm}$ per day) were required. Soil temperature and evaporation measurements were not always available and so the model was therefore modified to use daily measurements of maximum and minimum air temperatures and rainfall records as the input variables. These data records were more readily available from a wide range of sites. Other minor modifications have been incorporated into the original model to simplify its use and the program was rewritten in FORTRAN. Although reports have been published on the persistence and leaching of pesticides in the environment using mathematical models, very limited information on the subject is available for Malaysian environment. Therefore, the present study makes use of the PERSIST and VARLEACH models to investigate the credibility of the two modeling systems for predicting pesticide residues under tropical conditions as found in Malaysia. Fluroxypyr is currently widely used to control weeds in the Malaysian oil palm plantations.

PERSIST is a specific computer software designed by Janitha et al. (2006) to predict the persistence of pesticides in the soil. It has been used successfully to predict pesticide persistence in soils in the United Kingdom and USA with parameters derived from laboratory incubation studies (Lanyi and Dinya, 2005). Studies comparing the observed and predicted residues under tropical conditions such as those found in Malaysia are very limited (Ismail and Kalithasan, 2002). A modeling study using the Hornsby Index, Attenuation Factor and chemical movement in layered soils (CMLS) on 14 pesticides used in cabbage and chrysanthemum farms at the Cameron Highlands, Pahang, Malaysia, demonstrated that only methamidophos had the highest leaching potential (Maznah et al., 2010; Tayeb et al., 2015). A report on the dissipation of permethrin in the Malaysian agricultural soils was documented, where the predicted data derived from the model showed higher values than the observed data (Ismail and Kalithasan, 2002).

The current study comparing the dissipation of fluroxypyr in a field experiment with the predicted values using the PERSIST and VARLEACH simulation would help in better understanding the fate of fluroxypyr in tropical soils such as those found in Malaysia. To the best of our knowledge, no report has been published on the use of a mathematical model on fluroxypyr dissipation in the Malaysian soils. Therefore, the main objective of this study was to investigate the possibility of using the PERSIST and VARLEACH models to predict herbicide residues in soils under tropical conditions as found in Malaysia.

\section{MATERIALS AND METHODS}

\section{Field Experiment}

Site selection. The study was conducted at the KLIA Oil Palm Plantation of the Malaysian Agricultural Horticultural Sdn Bhd (MAAH). This oil palm estate is situated in the central part of the state of Selangor in Peninsular Malaysia at altitude $70 \mathrm{~m}$ to $100 \mathrm{~m}$ above sea level. The study plot covered $6 \mathrm{ha}$, and consisted of nine subplots of 0.66 ha each. The study plot was situated on hilly land of slope $45^{\circ}$ with soil predominantly clayey in texture. The physicochemical properties of the soil were determined. The palm in the study plots were two and the half years old. The area has tropical climate with daily temperatures varying from $25^{\circ} \mathrm{C}$ to $36^{\circ} \mathrm{C}$, average daily humidity usually in excess of $80 \%$ and average monthly rainfall between 31-169 $\mathrm{mm}$.

Fluroxypyr 1-methyl heptyl ester (fluroxypyrMHE) was applied as an aqueous spray using a knapsack sprayer (nozzle 5/64) at spraying volume of 250 litres ha-1. The herbicide was applied at $72.05 \mathrm{~g}$ a.i. ha ${ }^{-1}$ in accordance to the manufacturer's recommended dosage. 
Soil sampling. Soil samples were collected from 0-50 $\mathrm{cm}$ depth using a soil auger and there were three replicates. The samples were taken at -1 (day before treatment), 0 (day of treatment) and 1, 5, 7, 14, 21, 30, 60 and 90 days after treatment. The soil samples were air-dried, sieved through a $2 \mathrm{~mm}$ mesh and stored in black polyethylene bags at $-4^{\circ} \mathrm{C}$ prior to analysis. The soil was classified as clay, containing $52.2 \%$ clay, a cation exchange capacity (CEC) of $6.9 \%, 15 \%$ coarse sand, $27 \%$ fine sand, $5.8 \%$ silt and $1.89 \%$ organic matter. The soil moisture content was $10.5 \%$ and $\mathrm{pH}$ of 4.5 .

Recovery study. Soil samples of $50 \mathrm{~g}$ were used in the study. The soil samples were spiked with fluroxypyr at five concentrations viz. 1, 5, 10, 25 and $50 \mu \mathrm{g} \mathrm{kg}^{-1}$. The pesticide was then extracted from the soil for residual determination.

Extraction of fluroxypyr residue from the soil samples. Soil samples of $5 \mathrm{~g}$ were placed into 250 $\mathrm{ml}$ conical flasks. Soil samples were spiked with standard fluroxypyr and the contents were mixed thoroughly on a vortex mixer. Each mixture was then allowed to stand for $15 \mathrm{~min}$ to enable homogenous distribution. Then $20 \mathrm{ml}$ of acetone: water (95:5, v/v) was added to each conical flask and the mixture was again mixed thoroughly for $30 \mathrm{~s}$ on a vortex mixer. Each conical flask was then placed in an ultrasonic bath for $15 \mathrm{~min}$ and then the content was transferred into individual test tube and centrifuged at high speed $(3500 \mathrm{rpm})$ at $26^{\circ} \mathrm{C}$, for $10 \mathrm{~min}$. The top layer (acetone + water) of each bottle was transferred to a Schott bottle using a glass Pasteur pipette and $200 \mathrm{ml}$ of fluroxypyr-free water were added to each bottle. The bottle was then stoppered and the content mixed by shaking for a few seconds. The bottle was then placed in an ultrasonic bath for $5 \mathrm{~min}$ and the $\mathrm{pH}$ of the mixture adjusted to 3.0 by the addition of $2 \mathrm{~N}$ $\mathrm{HCl}$. A SPE cartridge was attached to the manifold, which was pre-washed with $3 \mathrm{ml}$ acetonitrile and $3 \mathrm{ml}$ distilled water. The washings were discarded. The stopper was removed and the SPE tubing was immersed into the mixture. The aspirator was switched on for the water to be sucked through the OASIS $^{\circledast}$ HLB. The flow of the water through the SPE cartridge was controlled by a pressure knob so as to elute the water at $8-10 \mathrm{ml} \mathrm{s}^{-1}$. After the water was completely drawn through the SPE cartridge the bottle was rinsed with $5 \mathrm{ml}$ water. The water from the rinsing was also passed through the SPE cartridge and the cartridge was then vacuumdried. The fluroxypyr adsorbed in the cartridge was then eluted with $4 \mathrm{ml}$ acetonitrile. The eluate was dried completely in vacuum. The residue was then redissolved in $1 \mathrm{ml}$ acetonitrile before being injected into the high performance liquid chromatographydiode array detector (HPLC-DAD). Quantification of the analyte was made by comparing it with the fluroxypyr standard solution. There were five replicates and each solution was injected twice.

HPLC analysis. An Agilent HPLC 1100 Series fitted with a DAD was used for the analysis. The column used was a LUNA RP18, $5 \mu \mathrm{m}(250 \mathrm{~mm} \times 4.6 \mathrm{~mm}$ I.D.). A guard cartridge RP 18, $5 \mu \mathrm{m}$ (Phenomenex) with the RP-18 column was used. The wavelength was set at $254 \mathrm{~nm}$. The mobile phase was acetonitrile and acetate buffer (1\% acetic acid in water) in the ratio of $60: 40(\mathrm{v} / \mathrm{v})$. The flow rate and injection volume were $0.8 \mathrm{ml} \mathrm{min}^{-1}$ and $100 \mu \mathrm{l}$, respectively.

Prediction of persistence by the PERSIST model. The simulation of PERSIST on the prediction of persistence was undertaken using a personal computer. Inputs of the data required for the simulations were daily maximum and minimum air temperatures and daily rainfall records. The daily weather data was obtained from the Kuala Lumpur International Airport (KLIA) meteorological station. The weather data was taken from the first day of treatment up to 90 days after the treatment and was used as an input to simulate as close as possible the weather conditions of the field under study. The model also required the input of soil physical properties such as field capacity (at $5 \mathrm{kPa}$ suction) and soil bulk density. Pesticide properties such as half-life in soil moisture at specific temperatures were also required. The half-life value of the pesticide was derived from the field study. The known rate of pesticide application was also required. The geographical location of the plot such as latitude and altitude were prerequisites. The simulation of PERSIST was automatically run on a Microsoft platform. After running the model completely, the prediction would be automatically saved under a file name OUTPUT in the same folder with the program. The output of the simulation came in the standard column format with headings: DAYS (days after application), CONC (residual concentration of pesticide, \% of initial), SM (soil moisture content, $\%$ ), ST (mean soil temperature, ${ }^{\circ} \mathrm{C}$ ), PE (calculated potential pan evaporation, $\mathrm{mm}$ ) and HL (calculated half-life, days).

Prediction of persistence by the VARLEACH model. The same data input used in the PERSIST model was subjected to another simulation model, the VARLEACH model. VARLEACH is a modified version of PERSIST, and it simulates the leaching of the pesticide in the soil profile. For the VARLEACH model, additional inputs were required, namely, the adsorption distribution coefficient constant and water solubility. After a complete run of the VARLEACH program, the prediction would be automatically saved under a file name RESULT. The 
file was under the TXT extension, which contained the predicted value of the total pesticide residues in the soil profile at different depths.

Calculation of the Coefficient of Residue Mass for PERSIST and VARLEACH. The degree of agreement between the predicted and the observed values was evaluated using the Coefficient of Residual Mass (CRM) (Vanclooster et al., 2000; Lesueur, 2008). CRM is obtained by dividing the predicted value with the observed value. A value of CRM $>1$ indicates that the model over estimated the observed value, while a value of CRM $<1$ indicates that the model under estimated the observed value. A perfect agreement between predicted and observed values would be characterised by the value of $C R M=1$. If the difference is within $30 \%$ of the observed value, the model is considered as practically accurate in predicting residues for the subsequent crops (Lourencetti, 2008).

\section{RESULTS AND DISCUSSION}

\section{Recovery Study}

The recovery and relative standard deviation percentage of fluroxypyr-spiked soil samples at levels of $1,5,10,25$ or $50 \mu \mathrm{g} \mathrm{kg}^{-1}$ using OASIS ${ }^{\circledR}$ HLB (Table 1) were $107 \pm 0.5 \%, 100 \pm 4.7 \%, 101 \pm 2.5 \%$, $100 \pm 0.7 \%$ and $82 \pm 0.9 \%$, respectively with relative standard deviation ranging from $0.5 \%$ to $4.7 \%$. The linear regression $(r)$ was found to be 0.9989 and the equation derived from the calibration curve was $y=40039 x+200.15$, where $y$ was the peak height of fluroxypyr butyl ester obtained from gas chromatography (GC) analysis and $x$ was the concentration of fluroxypyr in $\mu \mathrm{g} \mathrm{ml}^{-1}$. The detection limit of fluroxypyr was $4 \mu \mathrm{g} \mathrm{kg}^{-1}$.

\section{Field Experiment}

Chromatograms shown in Figures $1 a, 1 b$ and $1 c$ are fluroxypyr in standard solution, untreated and treated soil samples respectively. The retention time of fluroxypyr was $8.9 \mathrm{~min}$. Table 2 shows the residue concentrations of fluroxypyr in the soil. The fluroxypyr residue was detected at $10-50 \mathrm{~cm}$ depth at one day after treatment (DAT) at the recommended dosage. At $1 \mathrm{DAT}$, the highest concentration $(44 \mu \mathrm{g}$ $\mathrm{kg}^{-1}$ ) was recorded at the depth of 30-40 cm followed by that at the deepest layer $(40-50 \mathrm{~cm}$ depth), which had a concentration of $35 \mu \mathrm{g} \mathrm{kg}$. The fluroxypyr concentration decreased with time of sampling. The concentration of fluroxypyr at the top $10 \mathrm{~cm}$ of the soil decreased faster than that in the lower profile. No residue was detected at the depth of $0-20 \mathrm{~cm}$ at five days after treatment, while on seven days after treatment fluroxypyr residue was only found at the depth of $20-40 \mathrm{~cm}$. However, on Day 14 after treatment, no residue was detected, irrespective of the soil profile. Factors such as volatilisation, runoff, leaching, chemical and biological degradation as well as photolysis could have enhanced the degradation rate especially under tropical climatic conditions such as those found in Malaysia. Moreover, the high temperature, humidity and rainfall throughout the year could have contributed to the rapid loss of the pesticides from the experimental plot. Other factors besides the acceleration of pesticide degradation and dissipation under tropical conditions might also be responsible. One possible factor could be the nonuniform spraying of the pesticides that could have caused uneven pesticide distribution throughout the trial plot.

\section{PERSIST Prediction for Fluroxypyr}

The data obtained from the field study of fluroxypyr in the clay soil at the KLIA Oil Palm Plantation, was subjected to the PERSIST simulation model. Table 3 shows the PERSIST predicted values and the observed results of fluroxypyr studied in the clay soil at the KLIA Oil Palm Plantation, Sepang, Selangor, Malaysia. On Day 0 after spraying, there was perfect agreement obtained between the observed and predicted results with CRM $=1$. On Day 1 and 5 after spraying, the CRM values for PERSIST were 1.01 and 1.09, which is in almost perfect agreement between the observed and

TABLE 1. RECOVERY OF FLUROXYPYR FROM SPIKED SOIL SAMPLES USING OASIS ${ }^{\circledR} 200 \mathrm{mg}$ IN CLEAN-UP PROCESS

\begin{tabular}{ccc}
\hline $\begin{array}{c}\text { Concentration of } \\
\text { fluroxypyr }\left(\mu \mathbf{g ~ k g}^{-1}\right)\end{array}$ & $\begin{array}{c}\text { Recovery }(\%) \\
\mathbf{n = 5}\end{array}$ & $\begin{array}{c}\text { Relative standard deviation } \\
\mathbf{( \% )}\end{array}$ \\
\hline 1 & 107 & 0.5 \\
5 & 100 & 4.7 \\
10 & 101 & 2.5 \\
25 & 100 & 0.7 \\
50 & 82 & 0.9 \\
\hline
\end{tabular}


a)

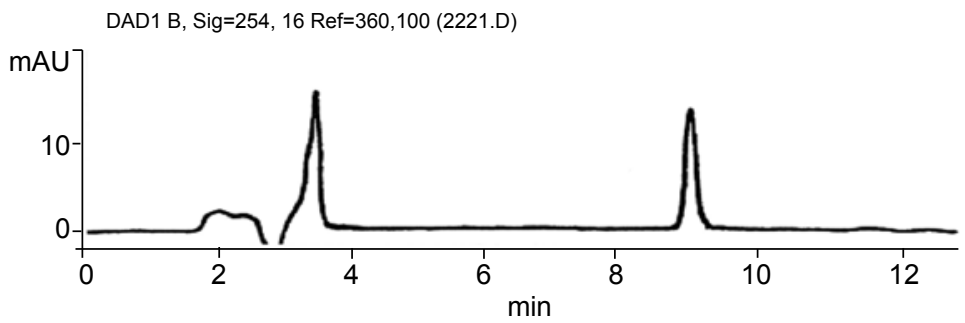

b)

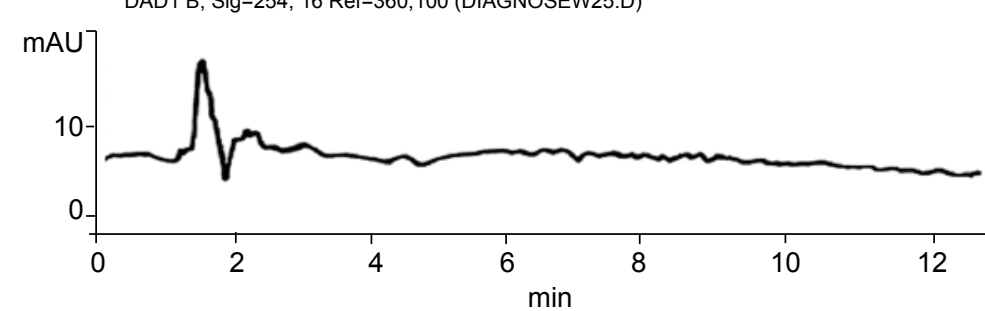

c)

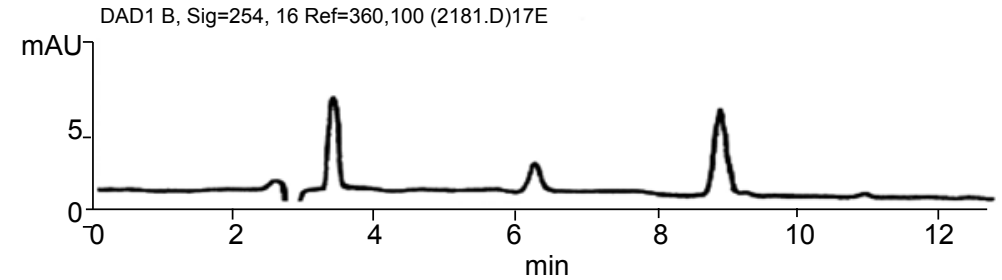

Figure 1. High performance liquid chromatography-diode array detector (HPLC-DAD) chromatograms of (a) untreated sample of soil, (b) standard fluroxypyr solution, $0.02 \mu \mathrm{g} \mathrm{ml}^{-1}$ and (c) spiked soil sample containing $0.05 \mu \mathrm{g} \mathrm{g}^{-1}$ of fluroxypyr.

TABLE 2. CONCENTRATION OF FLUROXYPYR RESIDUE IN SOIL SAMPLES TREATED AT THE MANUFACTURER'S RECOMMENDED DOSAGE

\begin{tabular}{|c|c|c|}
\hline DAT & $\begin{array}{l}\text { Depth } \\
\text { (cm) }\end{array}$ & $\begin{array}{l}\text { Concentration of } \\
\text { fluroxypyr }\left(\mu \mathrm{g} \mathrm{kg}^{-1}\right)\end{array}$ \\
\hline 1 & $\begin{array}{c}0-10 \\
10-20 \\
20-30 \\
30-40 \\
40-50\end{array}$ & $\begin{array}{c}\text { ND } \\
15 \pm 1.1 \\
28 \pm 2.1 \\
44 \pm 1.4 \\
35 \pm 2.1\end{array}$ \\
\hline 5 & $\begin{array}{c}0-10 \\
10-20 \\
20-30 \\
30-40 \\
40-50\end{array}$ & $\begin{array}{c}\text { ND } \\
\text { ND } \\
42 \pm 0.7 \\
29 \pm 0.7 \\
25 \pm 1.3\end{array}$ \\
\hline 7 & $\begin{array}{c}0-10 \\
10-20 \\
20-30 \\
30-40 \\
40-50\end{array}$ & $\begin{array}{c}\text { ND } \\
\text { ND } \\
25 \pm 0.7 \\
11 \pm 0.7 \\
\text { ND }\end{array}$ \\
\hline 14 & $\begin{array}{c}0-10 \\
10-20 \\
20-30 \\
30-40 \\
40-50\end{array}$ & $\begin{array}{l}\text { ND } \\
\text { ND } \\
\text { ND } \\
\text { ND } \\
\text { ND }\end{array}$ \\
\hline
\end{tabular}

Note: DAT - day after treatment.

$\mathrm{ND}$ - not detected $=<1 \mu \mathrm{g} \mathrm{kg}^{-1}$. predicted results. Results from the field observation indicated that fluroxypyr residue was not detected from Day 7 onwards, while the prediction form PERSIST showed that there would be fluroxypyr residue up to Day 7 after spraying (Figure 2).

The Day 1 and 5 after spraying; the percentage difference between observed and predicted values were $1.13 \%$ and $9.85 \%$, respectively (Table 3). However, these values were less than the allowable $30 \%$, so the prediction of PERSIST for fluroxypyr does conform very well with the observed values. Thus, the PERSIST model is acceptable for predicting fluroxypyr residue in soil.

\section{VARLEACH Prediction for Fluroxypyr Residue}

Predicted results for VARLEACH obtained from the computer program and results observed from the field trial are shown in Figure 3. The field trial values were lower than the predicted values except on the day of spraying (Day 0). Furthermore, the dissipation of fluroxypyr in the field trial was much faster than that predicted by VARLEACH. Fluroxypyr was detected in the soil on Day 0, 1 and 5 after spraying. Meanwhile, in the VARLEACH simulation, fluroxypyr was predicted to dissipate completely from Day 30 onwards. The dissipation time of fluroxypyr was longer in the VARLEACH prediction. This might be due to other factors such 


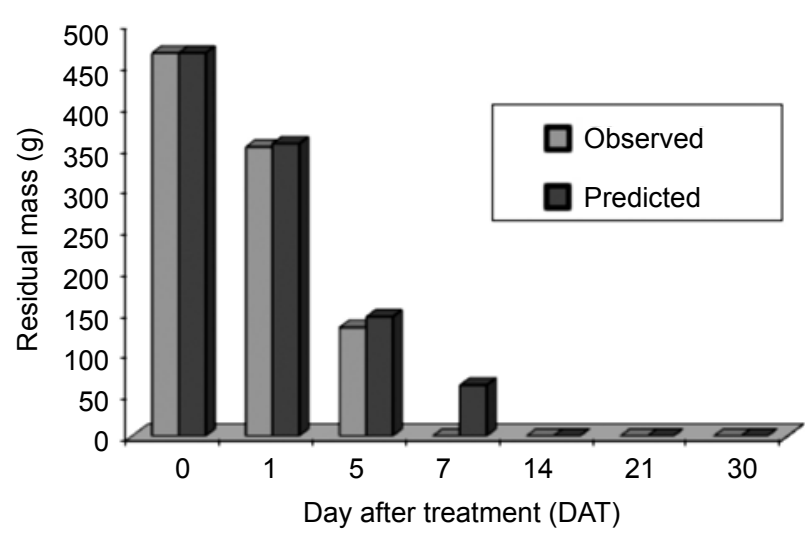

Figure 2. Measured and predicted dissipation of fluroxypyr in the soil (PERSIST simulation).

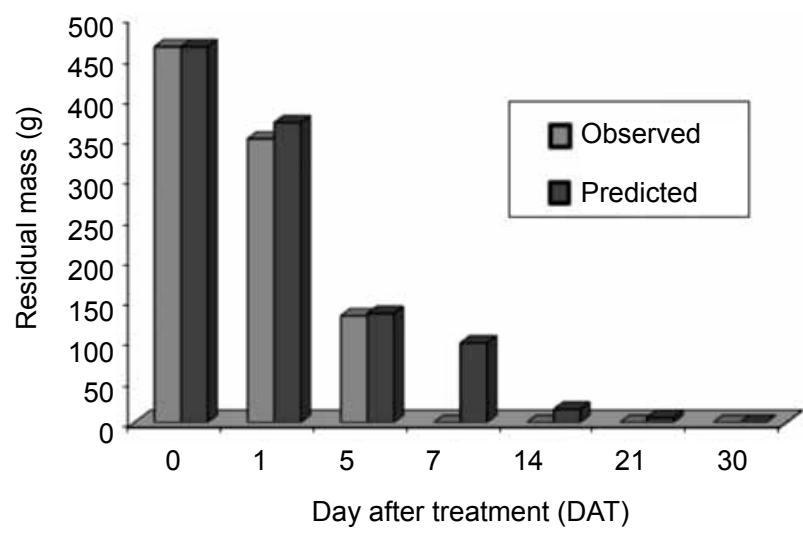

Figure 3. Observed and predicted dissipation of fluroxypyr in the soil (VARLEACH simulation). as volatilisation and microbial activity that may have contributed to rapid dissipation of fluroxypyr in the field trial. Similar findings on dissipation have been reported by Ismail and Kalithasan (2002), where the predicted data derived from the model showed higher values than the observed data. Tay (2012) also reported comparable results in which the VARLEACH model predicted the movement of propyzamide, linuron and isoxaben with considerable agreement to the field observation.

Predicted results for VARLEACH obtained from the computer program and data derived from the field trial are shown in Table 4. On Day 0 after treatment there was a perfect agreement between predicted and observed values since the value of CRM was equal to 1 and no differences were observed between model simulation and field trial results. The CRM values for VARLEACH on Day 1 and 5 after spraying were very close to 1 that is 1.05 and 1.02 , respectively, indicating that the simulation model gave only a very slight overestimation. Therefore, there was good agreement between data derived from the simulation model and that of the observed field results.

The differences between the simulation model and field trial data were very low, namely $0 \%$, $5.7 \%$ and $2.3 \%$ on Day 0, 1 and 5, respectively, after spraying (Figure 3). Therefore, we can conclude that the VARLEACH model values and field trial results for fluroxypyr compounds were in very good agreement.

TABLE 3. DEGREE OF AGREEMENT AND ACCURACY OF PERSIST MODELING FOR FLUROXYPYR RESIDUES IN SOIL

\begin{tabular}{ccc}
\hline Day & CRM for PERSIST & $\begin{array}{c}\text { \% Difference between observed and } \\
\text { PERSIST }\end{array}$ \\
\hline 0 & 1 & 0 \\
1 & 1.01 & 1.13 \\
5 & 1.09 & 9.85 \\
7 & - & - \\
14 & - & - \\
\hline
\end{tabular}

Note: CRM - Coefficient of Residual Mass.

TABLE 4. DEGREE OF AGREEMENT AND ACCURACY OF VARLEACH MODELING FOR FLUROXYPYR RESIDUES IN SOIL

\begin{tabular}{ccc}
\hline Day & CRM for VARLEACH & $\begin{array}{c}\text { \% Difference between observed and } \\
\text { VARLEACH }\end{array}$ \\
\hline 0 & 1 & 0 \\
1 & 1.05 & 5.7 \\
5 & 1.02 & 2.3 \\
7 & - & - \\
14 & - & - \\
\hline
\end{tabular}

Note: CRM - Coefficient of Residual Mass. 


\section{CONCLUSION}

PERSIST prediction for fluroxypyr residues in soils planted with oil palm was found to be accurate and conformed to the observed results. The model PERSIST predicted that fluroxypyr would remain longer in soil but the observed data indicated that the residue persisted in soil was for a shorter period compared to the predicted value. However, the dissipation rate of fluroxypyr predicted via modelling showed similar pattern to the observed data. It was evident that the VARLEACH model gave accurate predictions for fluroxypyr residues, in agreement with the observed results. The VARLEACH predictions and the observed data were in good agreement. There was a slight variability in the accuracy of the VARLEACH prediction for fluroxypyr. However, the predicted VARLEACH and observed values were well fitted to each other even though the VARLEACH values were overestimated. Therefore these models are useful in evaluating the persistence and mobility of fluroxypyr in the soil.

\section{REFERENCES}

AINIE, K; TAN, Y A; NORMAN, $\mathrm{K}$ and YEOH, C B (2007). Pesticide application in the oil palm plantation. Oil Palm Bulletin No. 54: 52-67.

BOESTON, J J T I (2000). From laboratory to field: uses and limitations of pesticide behavior models for the soil/ plant system. Weed Research, 40: 123-138. DOI: $10.1046 /$ j.1365-3180.2000.00158.x.

BUSZEWSKI, B; RUTKOWSKI, T; ZEBROWSKI, W and MICHEL, M (2006). Isolation and determination of urea herbicides in soil by hyphenated chromatographic techniques. Liquid Chromatography and Related Technologies, 29: 1933-1949. DOI: $10.1080 / 10826070600757854$.

CABRERA, A; COX, L; VELARDE, P; KOSKINEN, W C and CORNEJO, J (2007). Fate of diuron and terbuthylazine in soils amended with two-phase olive oil mile waste. Agriculture and Food Chemistry, 55: 4828-4838. DOI: 10.1081/PFC-100106184.

CHEAH, U B; MA, C K; DZOLKHIFLI, O; AINIE, K and CHUNG, G F (2001). Persistence of cypermethrin, deltamethrin and endosulfan in an oil palm agroecosystem. Proc. of the 2001 PIPOC International Palm Oil Congress. 20-22 August 2001, Kuala Lumpur, Malaysia. p. 105-113.

CHEFETZ, B; BILKIS, Y I and POLUBESOVA, T (2004). Sorption-desorption behavior of triazine and phenylurea herbicides in kishon river sediments. Water Research, 38: 4383-4394. DOI: 10.1016/j. watres.2004.08.023.

FARAHANI, G H N; ISMAIL, B S; ZURIATI, Z; AINIE, K and DZOLKIFLI, O (2008). Study on the downward movement of carbofuran in two Malaysian soils. Bulletin of Environmental Contamination and Toxicology, 81: 294-298. DOI: 10.1016/j.watres.2004.08.023.

FUAD, A and MAHER, T (2010). Analysis of azithromycin and its related compounds by RPHPLC with UV detection. J. Chromatographic Science, 48: 86-90. DOI: 10.1093/chromsci/ 48.2.86.

GIACOMAZZI, S and COCHET, N (2004). Environmental impact of diuron transformation: a review. Chemosphere, 56: 1021-1032. DOI: 10.1016/j. chemosphere.2004.04.061.

GOODDY, D C; CHILTON, P J and HARRISON, I (2002). A field study to assess the degradation and transport of diuron and its metabolites in calcareous soil. The Science of the Total Environmental, 297: 67-83. DOI: 10.1016/S0048-9697(02)00079-7.

GUARDIA-RUBIO, M; BANEGAS-FONT, V; MOLINA-DIAZ, A and AYORA-CANADA, M J (2006). Determination of triazine herbicides and diuron in mud from olive washing devices and soils using gas chromatography with selective detectors. Analytical Letters, 39: 835-850. DOI: $10.1080 / 00032710600611608$.

ISMAIL, B S and KALITHASAN, K (2002). Measurement and prediction of permethrin persistence in six Malaysian agricultural soils. Australian J. Soil Research, 40: 817-826. DOI: dx.doi. org / 10.1071/SR01097.

ISMAIL, B S; NGAN, C K; CHEAH, U B and WAN ABDULLAH, W Y (2004). Leaching potential of pesticides in a vegetable farm in the Cameron Highlands, Malaysia. Bulletin of Environmental Contamination and Toxicology, 72(4): 836-43. DOI: $10.1007 /$ s00128-004-0320-5.

ISMAIL, B S; PRAYITNO, S and TAYEB, M A (2015). Contamination of rice field water with sulfonylurea and phenoxy herbicides in the Muda Irrigation Scheme, Kedah, Malaysia. Environmental Monitoring Assessment, 187(7): 406. DOI: 10.1007/s10661-0154600-9.

JANITHA, A L; RANSILU, C W; PIYALARAVINNA, A G; LESTER, S and RAI, S K (2006). Sorption of carbofuran and diuron pesticides in 43 tropical soils 
of Sri Lanka. Agriculture and Food Chemistry, 54: 17841791. DOI: dx.doi.org/10.1081/PFC-100106184.

LANYI, K and DINYA, Z (2005). Photodegradation study for assessing the environmental fate of some triyazine-, urea-, and thiolcarbamate-type herbicides. Michrochemical, 80: 79-87. DOI: 10.1016/j. microc.2004.12.001.

LESUEUR, C; GARTNER, M; MENTLER, A and FUERHACKER, M (2008). Comparison of four extraction methods for the analysis of 24 pesticides in soil samples with gas chromatography-mass spectrometry and liquid chromatography-ion trap-mass spectrometry. Talanta, 75: 284-293. DOI: 10.1016/j.talanta.2007.11.031.

LIYANGE, J A; WATAWALAR, R C; ARAVINNA, A G P; SMITH, L and KOOKANA, R S (2006). Sorption of carbofuran and diuron pesticides in 43 tropical soils of Sri Lanka. Agricultural and Food Chemistry, 54: 1784-1791. DOI: dx.doi.org/10.1021/jf052021o.

LOURENCETTI, C; DEMARCHI, M R R and RIBEIRO, M L (2008). Determination of sugar cane herbicides in soil and soil treated with sugar cane vinasse by soild-phase and HPLC-UV. Talanta, 77(2): 701-709. DOI: 10.1016/j.talanta.2008.07.013.

MAZNAH, Z; ISMAIL, B S and HALIMAH, M (2010). Fate of thiram in oil palm nursery ecosystem during wet season. Proc. of the 2010 National Seminar: Palm Oil Milling, Refining, Environment and Quality (POMREQ).p. 396.
MOU, R X; CHEN, M X and ZHI, J L (2008). Simultaneous determination of 15 phenylurea herbicides in rice and corn using HPLC with fluorescence detection combined with UV decomposition and post-column derivatization. Chromatography B, 875: 437-443. DOI: 10.1016/j. jchromb.2008.09.022.

NGIM, K K; MABURY, S A and CROSBY, D C (2000). Elucidation of fipronil photodegradation pathways. J. Agricultural and Food Chemistry, 48: 4661-4665. DOI: $10.1021 /$ jf9913007.

TAY, B Y P (2012). Analysis of isopropyl paratoluenesulphonate in palm-based esters by gas chromatography with flame ionization detection and confirmed with mass spectrometry. International J. Cosmetic Science: 1-7. DOI: 10.1111/ics.12004.

TAYEB, M A; ISMAIL, B S; MARDIANA-JANSAR $\mathrm{K}$ and $\mathrm{GOH} \mathrm{CHOO}$ TA (2015). Glufosinate ammonium clean-up procedure from water samples using SPE. AIP Conference Proceedings. p. 1678. DOI:10.1063/1.4931351.

VANCLOOSTER, M; BOESTEN, J J T I; TREVISAN, M; BROWN, C D; CAPRI, E; EKLO, B; GOTTESBÜREN, O M; GOUYAND, V and VAN DER LINDEN, A M A (2000). A European test of pesticide leaching models: methodology and major recommendations. Agricultural Water Management, 44: 1-19. DOI: 10.1016/80378-3774(99)00081-5.

YING, G G and KOOKANA, R S (2001). Sorption of fipronil and its metabolites on soils from South Australia. J. Environmental Science and Health B, 36: 545-558. DOI: 10.1081/PFC-100106184. 